\title{
The Heats of Hydrolysis of Some Alkyl Acetates
}

\author{
I N G EMAR WADSÖ
}

Thermochemistry Laboratory, University of Lund, Sweden

\begin{abstract}
The heats of hydrolysis of some alkyl acetates have been determined at $25^{\circ} \mathrm{C}$. For the idealized, isothermal hydrolysis reactions

$$
\mathrm{ROAc}(\mathrm{l})+\mathrm{H}_{\mathbf{2}} \mathrm{O}(\mathrm{l}) \rightarrow \mathrm{ROH}(\mathrm{l})+\mathrm{HOAc}(\mathrm{l})
$$

the enthalpy changes were found as follows:

$0.89 \pm 0.04 \mathrm{kcal} / \mathrm{mole}$ for $\mathrm{R}=\mathrm{Et}$; $0.80 \pm 0.05 \mathrm{kcal} / \mathrm{mole}$ for $\mathrm{R}=n-\mathrm{Bu}$; $0.54 \pm 0.05 \mathrm{kcal} / \mathrm{mole}$ for $\mathrm{R}=i$-Pr. These data have been com. pared with the corresponding values for the hydrolysis of thiolesters.
\end{abstract}

Tn previous papers the heats of hydrolysis of thiolacetic acid ${ }^{1}$ and of some 1 alkyl thiol acetates ${ }^{2}$ have been reported. In continuing the study of the thermochemistry of acyl derivatives and transacylation processes of biochemical interest it was felt important to determine heats of hydrolysis for some simple alkyl acetates.

\section{EXPERIMENTAL}

Materials. The esters were commercially available preparations. They were purified by distillation through a 10-plate column. Purities were found to be $99.9 \%$ or better as judged by measurements of equivalent weights. These were determined after alkaline hydrolysis by titration of acetic acid. The hydrolysis was carried out in alcohol - water solution containing 2 moles of $\mathrm{NaOH}$ per mole of ester. After $12 \mathrm{~h}$ the sample was titrated potentiometrically with $0.1 \mathrm{~N} \mathrm{HCl}$.

Table 1. Equivalent weight, density and refractive index for the esters ROAc.

\begin{tabular}{|c|c|c|c|c|}
\hline \multirow{2}{*}{$\mathbf{R}$} & \multicolumn{2}{|c|}{ Equivalent weight } & \multirow{2}{*}{$d_{4}^{25}$} & \multirow{2}{*}{$n_{\mathrm{D}}^{25}$} \\
\hline & Found & Theoretical & & \\
\hline $\begin{array}{l}\text { Et } \\
n-\mathrm{Bu} \\
i \text {-Pr }\end{array}$ & $\begin{array}{r}88.15 \\
116.16 \\
102.20\end{array}$ & $\begin{array}{r}88.10 \\
116.16 \\
102.13\end{array}$ & $\begin{array}{l}0.8950 \\
0.8758 \\
0.8709\end{array}$ & $\begin{array}{l}1.3707 \\
1.3928 \\
1.3757\end{array}$ \\
\hline
\end{tabular}

Auxiliary substances. Alcohols used for heats of solution measurements were thoroughly dried and distilled. Acetic acid was purified by freezing out 4 times. Its purity was found to be $100.0 \%$ (potentiometric titration with $\mathrm{NaOH}$ ). 
Apparatus. The reactions were carried out in an isothermal calorimeter, which will be described in detail elsewhere ${ }^{8}$. The calorimeter consisted of a steel reaction vessel with stirrer, heating element, and a thermistor (Stantel U 236120) for measuring the temperature changes.

Calibration. The heat capecity of the calorimeter was determined electrically by passing a known current for a given time $(240-315 \mathrm{sec})$ through the heating element. The calibrations were carried out on the system after the hydrolysis. In the runs, corrections were made for the small differences in heat capacity of the ampoule and its content.

Heat of reaction measurements. The calorimeter was charged with $90 \mathrm{ml}$ of $0.8 \mathrm{~N}$ sodium hydroxide solution in water-ethanol $(2: 3)$. The sealed glass ampoule contained about 3 mmoles of ester (alcohol, acetic acid or water). The reaction was completed within 5 min, the duration of the reaction period was $8 \mathrm{~min} *$. The initial and final thermistor resistance ( $R_{\mathrm{i}}$ and $R_{\mathrm{f}}$, respectively) could therefore be obtained graphically without introducing significant errors.

Corrections to standard states. The ideal isothermal hydrolysis reaction $\mathrm{V}$ is obtained from eqns. I to IV, corresponding to the reactions taking place under actual experimental conditions.

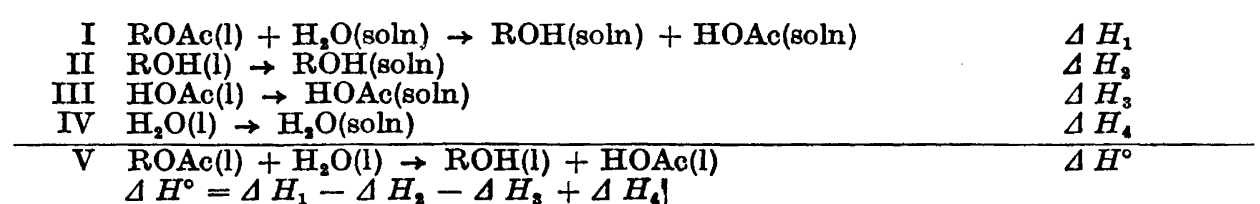

Units of measurement. The results of the calorimetry experiments are expressed in terms of the defined calorie equal to 4.1840 abs. joules and refer to the isothermal process at $25^{\circ}$ and to the true mass.

The molecular weights were computed from the 1951 table of international atomic weights 4.

\section{RESULTS}

The experimental results are summarised in Tables 2 to 5 . Table 2 gives the results of a series of calibration experiments. The following symbols have been used:

$$
q \quad \text { input of electrical energy }
$$

$\log R_{\mathrm{i}} / R_{\mathrm{f}}$ the expression proportional to the temperature change;

$R_{\mathrm{i}}$ and $R_{\mathrm{f}}$ are the thermistor resistance values at the start and the end, respectively, of the main period

$\varepsilon$ the heat capacity of the calorimetric system in calories per unit of $\log R_{\mathrm{i}} / R_{\mathrm{f}}$

Table 2. Calibration experiments.

$\begin{array}{lrc}q, \text { cal } & 10^{4} \times \log R_{\mathrm{i}} / R_{\mathrm{f}} & \left\lceil\varepsilon \times 10^{-2}\right. \\ 37.28 & 64.42 & 57.87 \\ 37.25 & 64.34 & 57.90 \\ 48.85 & 84.63 & 57.72 \\ 41.89 & 72.45 & 57.82 \\ & & 57.83 \pm 0.04 * *\end{array}$

* Attempts to determine the heat of hydrolysis of $t$-BuOAc with this apparatus failed due to the slowness of the hydrolysis.

** All the uncertainties are given as the standard deviation of the mean.

Acta Chem. Scand. 12 (1958) No. 4 
In Table 3, the first column identifies $R$ in ROAc, the second gives the amount of ester hydrolyzed, the fourth gives the amount of heat evolved during the experiment, and the last column gives the enthalpy change.

Table 3. Determination of heats of hydrolysis of somej alkyl esters, ROAc.

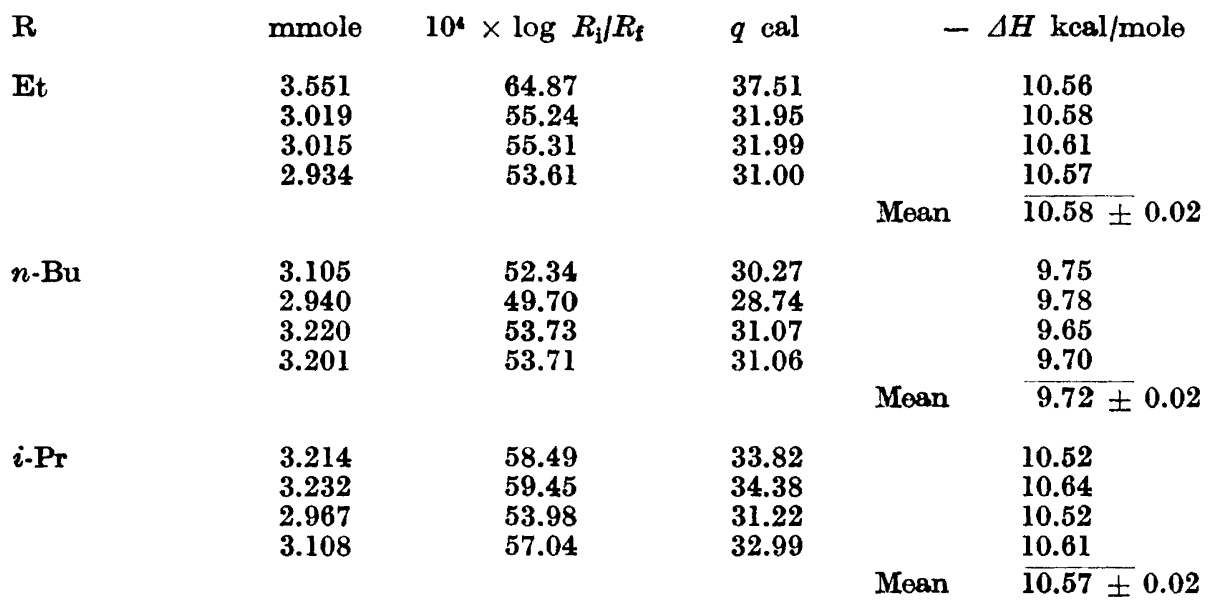

Table 4. Heats of solution measurements.

\begin{tabular}{|c|c|c|c|c|c|}
\hline Substance & mmole & $10^{4} \times \log \mathbf{R}_{\mathrm{i}} / \mathbf{R}_{\mathrm{f}}$ & $q(\mathrm{cal})$ & & $\triangle H \mathrm{kcal} / \mathrm{mole}$ \\
\hline EtOH & $\begin{array}{l}3.333 \\
3.339 \\
\mathbf{3 . 2 1 5}\end{array}$ & $\begin{array}{l}0.27 \\
0.20 \\
0.30\end{array}$ & $\begin{array}{l}0.16 \\
0.12 \\
0.17\end{array}$ & Mean & $\begin{array}{l}0.05 \\
0.04 \\
0.05 \\
0.05 \pm 0.01\end{array}$ \\
\hline$n$-BuOH & $\begin{array}{l}3.117 \\
3.141 \\
3.452\end{array}$ & $\begin{array}{l}-4.59 \\
-5.04 \\
-5.47\end{array}$ & $\begin{array}{l}-2.65 \\
-2.91 \\
-3.16\end{array}$ & Mean & $\begin{array}{l}-0.85 \\
-0.93 \\
-0.92 \\
-0.90 \pm 0.03\end{array}$ \\
\hline$\overline{i-\mathrm{PrOH}}$ & $\begin{array}{l}3.288 \\
2.992 \\
3.732\end{array}$ & $\begin{array}{l}-1.97 \\
-1.55 \\
-1.86\end{array}$ & $\begin{array}{l}-1.14 \\
-0.90 \\
-1.07\end{array}$ & Mean & $\begin{array}{l}-0.35 \\
-0.30 \\
-0.29 \\
-0.31 \pm 0.03\end{array}$ \\
\hline HOAc & $\begin{array}{l}3.340 \\
3.384 \\
3.466 \\
3.291\end{array}$ & $\begin{array}{l}66.72 \\
68.26 \\
69.78 \\
66.20\end{array}$ & $\begin{array}{l}38.54 \\
39.43 \\
40.30 \\
38.24\end{array}$ & Mean & $\begin{array}{l}11.54 \\
11.65 \\
11.63 \\
11.62 \\
11.61 \pm 0.03\end{array}$ \\
\hline$\overline{\mathrm{H}_{2} \mathrm{O}}$ & $\begin{array}{l}.982 \\
4.009\end{array}$ & $\begin{array}{l}0.98 \\
1.29\end{array}$ & $\begin{array}{l}0.57 \\
0.74\end{array}$ & Mean & $\begin{array}{l}0.19 \\
0.18 \\
0.19 \pm 0.01\end{array}$ \\
\hline
\end{tabular}

Table 5 contains a summary of the obtained data and the heat of hydrolysis of the idealized reaction $\mathrm{V}, \Delta H^{\circ}$. 
Table 5.

\begin{tabular}{|c|c|c|c|c|c|}
\hline $\mathrm{R}$ & $-\Delta H_{1}$ & $-\Delta H_{2}$ & $-\Delta H_{3}$ & $-\Delta H_{4}$ & $-\Delta H^{\circ}$ \\
\hline $\begin{array}{l}\text { Et } \\
n-\mathrm{Bu} \\
i \text {-Pr }\end{array}$ & $\begin{array}{r}10.58 \\
9.72 \\
10.57\end{array}$ & $\begin{array}{r}0.05 \\
-0.90 \\
-0.31\end{array}$ & $\begin{array}{l}11.61 \\
11.61 \\
11.61\end{array}$ & $\begin{array}{l}0.19 \\
0.19 \\
0.19\end{array}$ & $\begin{array}{l}-0.89 \pm 0.04 \\
-0.80 \pm 0.05 \\
-0.54 \pm 0.05\end{array}$ \\
\hline
\end{tabular}

\section{DISCUSSION}

Previously the heat of hydrolysis of EtOAc has been determined by Berenger-Calvet ${ }^{5}$. The value obtained by her is in resonably good agreement with that obtained in the present work. No other calorimetric determination of heats of hydrolysis of alkyl acetates has been found in the literature.

Unfortunately, there is an appreciable uncertainty in the heat of formation value for acetic acid ${ }^{1}$. Therefore, heat of hydrolysis values derived from heat of formation data cannot be calculated with the desired accuracy at the present time.

Table 6. Comparison between values of heats of hydrolysis of ROAc and RSAc in the liquid state.

\begin{tabular}{lccc|c}
\hline & & \multicolumn{2}{c|}{$\Delta H^{\circ}, \mathrm{kcal} / \mathrm{mole}$} & \\
\cline { 3 - 5 } & $\mathrm{R}$ & $\mathrm{ROAc}$ & $\mathrm{RSAc}$ & Difference \\
\hline & & 0.89 & -0.95 & \\
$\mathrm{Et}$ & & 0.80 & -1.09 & 1.84 \\
$n-\mathrm{Bu}$ & & 0.54 & -1.39 & 1.89 \\
$i$-Pr & & & 1.93 \\
\hline
\end{tabular}

As has been stated before ${ }^{2}$, there is only a small difference between the standard heats of hydrolysis for alkyl thiolesters and alkyl O-esters in the liquid state. Table 6 shows that this difference for $\mathrm{Et}, n$-Bu and $i$-Pr amounts to less than $2 \mathrm{kcal} / \mathrm{mole}$. However, if the reactions are compared in the gaseous state (Table 7) there is a much greater difference, depending on the high heats of vaporisation of alcohols compared with those of the corresponding thiols. The heats of vaporisation of esters, alcohols and thiols were calculated from the equations given by Klages ${ }^{6}$. The heat of vaporisation of acetic acid ${ }^{7}$ (monomeric vapor) and water $^{8}$ were taken to 12.5 and $10.5 \mathrm{kcal} / \mathrm{mole}$, respectively.

Table 7. Comparison between heats of hydrolysis of ROAc and RSAc in the gaseous state.

\begin{tabular}{lccc|c}
\hline & \multicolumn{2}{c|}{$\Delta H^{\circ}, \mathrm{kcal} / \mathrm{mole}$} & \\
\cline { 2 - 4 } & $\mathrm{ROAc}$ & $\mathrm{RSAc}$ & Difference \\
\hline $\mathrm{Et}$ & & 5.0 & -1.7 & \\
$n-\mathrm{Bu}$ & 5.0 & -1.5 & 6.7 \\
$i-\mathrm{Pr}$ & $\mathbf{4 . 4}$ & -2.0 & 6.5 \\
\hline
\end{tabular}

Acta Chem. Scand. 12 (1958) No. 4 


\section{REFERENCES}

1. Sunner, S. and Wadsö, I. Trans. Faraday Soc. 53 (1957) 455.

2. Wadsö, I. Acta Chem. Scand. 11 (1957) 1745.

3. Sunner, S. and Wadsö, I. Acta Chem. Scand. To be published.

4. Wichers, E. J. Am. Chem. Soc. 74 (1952) 2447.

5. Berenger-Calvet, Mme J. Chim. Phys. 24 (1927) 325.

6. Klages, E. Chem. Ber. 82 (1949) 358.

7. Parks, G. S. and Huffman, H. M. The Free Energies of Some Organic Compounds. Catalog Company Inc. 1932.

8. Selected Values of Chemical Thermodynamic Properties (SVCTP), Natl. Bur. Standards Circ. 500, Washington 1950.

Received January 24, 1958. 